\title{
Avaliação da potencia de membros superiores em atletas de voleibol feminino durante
}

\section{macrociclo de treinamento.}

\author{
Luiz Carlos Spínola Silveira Júnior $(I C)^{1}$, Aline Colares (PG) ${ }^{1}$, e Prof. Dr. João Paulo Borin (PQ) ${ }^{1}$. \\ 1 Grupo de Estudo em Teoria e Metodologia do Treinamento Desportivo - FEF/UNICAMP
}

\section{Resumo}

A potencia muscular de membros superiores é uma capacidade de destaque no âmbito do voleibol. Nesse sentido o objetivo do presente trabalho foi analisar a resposta da potencia muscular de membros superiores em oito semanas de treinamento. Nove atletas da categoria juvenil feminina, com idade entre 16 e 18 anos, foram avaliadas em dois momentos: início (M0) e final do período (M1), por meio do teste de arremesso de medicine ball. Após a coleta dos dados, os valores produziram informações no plano descritivo e inferencial.

Palavras Chave: treinamento, potencia, voleibol.

\section{Introdução}

Desde sua criação o voleibol passou por grandes evoluções, tanto tática quanto tecnicamente e o componente físico dos atletas também acompanhou tal comportamento, principalmente a potencia muscular. Nesse sentido a proposta do presente trabalho foi analisar o efeito de oito semanas de treinamento na potencia muscular de membros superiores em atletas de voleibol durante o período preparatório. Participaram do estudo 9 atletas de voleibol, da categoria juvenil, e durante o período de treinamento foi avaliada a potencia muscular, por meio do arremesso de medicine ball (Johnson, Nelson, 1979), no início (M0) e ao final do período (M1). A distribuição da organização do treinamento é apresentada no gráfico 1. Após a coleta dos dados da potencia, produziram-se informações no plano descritivo (média e desvio-padrão) e inferencial (teste $t$ de Student)..

\section{Resultados e Discussão}

A partir dos dados coletados os principais resultados são apresentados no gráfico 2. Apesar de verificar sensível elevação de $M 0(325,2 \mathrm{~cm})$ para M1 (339,3 cm), nota-se que não foi significativa $(p>0,05)$. Tais resultados são discutidos considerando dois fatores no âmbito do Treinamento Desportivo: o conteúdo de treinamento aplicado e a adaptação das atletas no período de treinamento analisado.

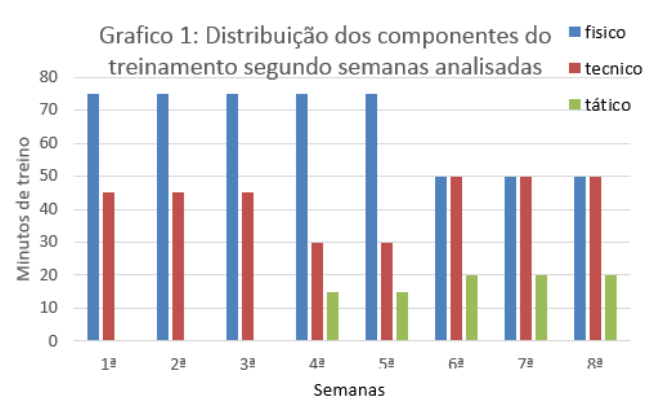

Gráfico 2: Média geral do grupo

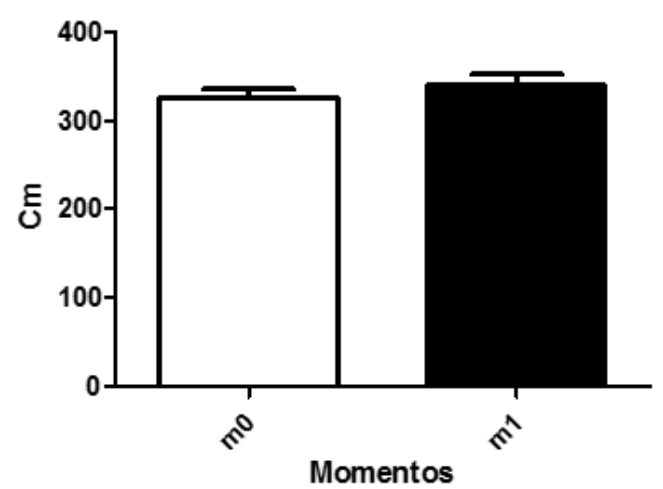

Conclusões

A partir dos resultados conclui-se que o período de oito semanas de treinamento, no período de treinamento, não foi suficiente para melhoria significativa da potencia dos membros inferiores em atletas de voleibol.

\section{Agradecimentos}

\section{_ PIBIC, CNPq, FEF - Unicamp}

1 JOHNSON, B.L., NELSON, J.K. Practical Measurements for Evaluation in Physical Education. Mineapolis: Burgess, 1979

2 OLIVEIRA P . O modelo das cargas concentradas de força. In. Oliveira P (Org.). Periodização contemporânea do treinamento desportivo. São Paulo: Phorte. p. 44. 2008. 